\title{
The Clinical Effect of Diode Laser in the Treatment of the Periodontal Pockets in Comparison with the Use of Photodynamic Therapy
}

\author{
Mohamed AA Quriba ${ }^{1 *}$, Tarek Harash ${ }^{2}$, Naieven Helmy ${ }^{3}$ \\ ${ }^{1} \mathrm{Ph} . \mathrm{D}$ Researcher, Laser National Institute (NILES), Egypt \\ ${ }^{2}$ Professor of Dental Laser Application (NILES), Egypt \\ ${ }^{3}$ Lecturer of Microbiology National Research Center, Egypt
}

\begin{abstract}
*Corresponding Author: Mohamed AA Quriba, PHD Researcher Laser National Institute (NILES), Egypt; Email: mohamedquriba@yahoo.com
\end{abstract}

Received Date: 03-03-2021; Accepted Date: 24-03-2021; Published Date: 01-04-2021

Copyright $^{\odot} 2021$ by Quriba MAA, et al. All rights reserved. This is an open access article distributed under the terms of the Creative Commons Attribution License, which permits unrestricted use, distribution and reproduction in any medium, provided the original author and source are credited.

\begin{abstract}
Periodontal diseases a group of microbial infections that's found in gingiva and supporting tissues of the teeth. The effect of microorganisms in the periodontitis could be confirmed. Purpose: The current study was conducted to evaluate the effects of diode laser versus Photodynamic Therapy (PDT) in periodontitis treatment as non-surgical method of treatment.

Materials and Methods: Thirty patients' males and females suffering from gingival pockets with age range from 20 to 65 years old from faculty of oral and dental medicine out clinics and selected randomly and divided in 2 groups each group contains fifteen patients. Group A received scaling and root planning in addition to $980 \mathrm{~nm}$ diode laser while Group B group received scaling and root planning in addition to PDT.
\end{abstract}

Results: showed statistically significance improvement in group A $(\mathrm{F}=114.697, \mathrm{P}=0.000)$ and in group $\mathrm{B}(\mathrm{F}=126.308, \mathrm{P}=0.000)$. Also, there was statistically significant difference between the two groups $(\mathrm{F}=5.904, \mathrm{P}=0.000)$ with most difference in Pocket Depth only $(\mathrm{F}=21.122$, $\mathrm{P}=0.000)$ with statistically significant differences in post treatment value $(\mathrm{F}=2.333, \mathrm{P}=0.000)$ and follow up at one $(\mathrm{F}=0.700, \mathrm{P}=0.019)$ and six months $(\mathrm{F}=1.100, \mathrm{P}=0.000)$. 
Conclusion: Both PDT and Diode therapy have significant effect in pocket depth, bacterial count and bleeding examination in periodontitis treatment, but PDT have Superior effect when pocket depth is the target.

\section{Keywords}

Diode Laser; Photodynamic Therapy; Periodontitis

\section{Introduction}

Periodontal diseases a group of microbial infections that's found in gingiva and supporting tissues of the teeth. The effect of microorganisms in the periodontitis could be confirmed. Periodontal diseases are usually treated by mechanical procedures that include scaling, root planning in and plaque control. As we know mechanical therapy mainly provides long term stability, but it also fails to eliminate the pathogenic bacteria completely and do not produce complete elimination of the disease [1].

Periodontitis is a multifactorial disease, that causes destruction of the periodontium is a result of interactions between a subgingival microbes and host defense mechanism. Usual treatment of periodontal disease includes mechanical debridement of the tooth to disrupt the microflora and provide a cleaner and biologically compatible root. However, mechanical scaling has low efficiency in deep pockets and in furcation areas. Limited access causes improper mechanical scaling and so, treatment planes including antimicrobials in association with mechanical debridement more favourable [2].

Complete removal of bacteria may be difficult, especially in case of of deep periodontal pockets. E.g.: patients with chronic periodontitis, had full-mouth scaling and root planning within $48 \mathrm{~h}$ showed reduced number of pockets more than $4 \mathrm{~mm}$ and bleeding on probing from 30 to three per subject [3].

Use of Dental lasers in the periodontal disease treatment can decrease the bacteria's total numbers in the gingival tissue, and so decreases the need for antibiotics [4].

Use of diode laser, with a wavelength between 655 and 980, usually with soft tissues not with dental hard tissues. It is used only for soft tissue, and also for sulcular mechanical debridement and for curettage. Moritz, et al., said that pocket treatment with a diode (805 nm) after scaling decrease bacteria numbers in the pockets more than using scaling alone. Bleeding on probing also and pocket showed better results with laser [5]. 
Photodynamic Therapy (PDT) appeared as a non-invasive therapeutic technique for the treatment of bacterial, fungal, and viral infections [6].

PDT can be used topically inside the periodontal pocket to avoid overdoses and drawbacks of the systemic antimicrobial treatments. It decreases the bacterial resistance [6,7].

PDT antimicrobial treatments can be used as an alternate to antibacterial, antifungal, and antiviral treatment to overcome the drug resistant organisms [8]. Use of Photo Dynamic Therapy in dentistry are increasing and they can be used as a treatment of oral cancer, bacterial and fungal infections, and in the diagnosis of the malignant tumors of oral lesions [9].

\section{Literature Review}

Periodontal disease means infection that can effects on both inflammatory and immune responses and causes destruction of periodontal structures, with an increased pocket depth, clinical attachment loss, besides destruction of alveolar bone. These changes finally causes tooth loss. The presence of bacterial plaque biofilm is the main etiologic factor that's causes the initiation of inflammatory periodontal diseases [10].

Periodontal therapy aims at arresting further loss of periodontal attachment and to ensure an aesthetic outcome. Periodontal disease can be treated with surgical or non-surgical techniques. Non-surgical therapy, includes, Scaling and Root Planning (SRP) but usually cannot be used for the complete healing of the disease, due to poor access to the floor of deep periodontal pockets [11]. However, scaling and root planning showed low efficacy, in deep pockets or furcations, due to leaving some accretions behind. So, treatment planes using antimicrobials with SRP have been provoked. Removal or decreasing of periodontal microorganisms in the subgingival pockets is necessary for periodontal healing [12].

Oral irrigation used as an alternative for dental floss, but now it must be included as a regular part of daily oral hygiene.

Data have demonstrated that SRP alone has limited effect on some pathogenic species, which may result in therapeutic failure. The use of antimicrobial agents in association to conventional therapy has been proposed as a therapeutic alternative In general, success in antimicrobial therapy is dependent on the appropriate choice of the antibiotic and the capacity of the drug to achieve an appropriate level of efficiency at the site of infection. Clinical trials showed that the use of systemic antimicrobial agents causes more periodontal improvement [13]. 
Actinobacillus actinomycetemcomitans, one of the most important types of bacteria that plays an etiological role in the development of periodontal disease which is very difficult to be treated [14].

The ability of the Photo Dynamic Therapy for treating periodontitis in adults, as a treatment alone or as an adjunct to non-surgical treatment, was oblivious [1].

Although, use of low wavelength lasers in deep tissue penetration but do not interact with the periodontal tissues within the pocket. So use of PDT with low-level laser therapy does not cause any thermal change within the gingival tissue or root surface [2].

\section{Aim of Study}

The aim of the present study is to compare the clinical effect of the diode laser application in the treatment of the periodontal pockets in comparison to the use of Photodynamic Therapy (PDT).

\section{Materials and Methods Subjects, Materials and Methods}

Thirty patients' males and females suffering from gingival pockets with age range from 20 to 65 years old from faculty of oral and dental medicine out clinics and selected randomly and divided in 2 groups each group contains fifteen patients.

\section{Subjects}

LASER diode group was treated with $980 \mathrm{~nm}$ diode laser only for 60 second in each point from the distal aspect of the $2^{\text {nd }}$ molar to the distal aspect of the canine in the lower arch points and with power of 1 watt. These processes would be repeated twice weekly for 3 weeks.

PDT group was treated with Scaling and root planning is to be carried out before PDT. While doing the PDT, the photosensitizer is first infused in the periodontal pocket and allowed to pigment for $2 \mathrm{~min}$. Then the fiber is inserted $1 \mathrm{~mm}$ short of the pocket and lased by moving in a sinusoidal manner from side to side toward the coronal third only for 60 second in each point from the distal aspect of the $2^{\text {nd }}$ molar to the distal aspect of the canine in the lower arch points and with power of 1 watt. These processes would be repeated twice weekly for 3 weeks. In antimicrobial PDT, photosensitizers used are toluidine blue $\mathrm{O}$ and methylene blue. Both have similar chemical and physicochemical characteristics. Toluidine blue $\mathrm{O}$ is a solution that is blue violet in color. It stains granules within mast cells and proteoglycans/glycosaminoglycans 
within connective tissues. Methylene blue is a redox indicator that is blue in an oxidizing environment and becomes colourless upon reduction.

Then follow up will be made one month later, 3 months later and 6 months later. Before starting the treatment and in each time of the 3 follow up sessions we will take a sample from the deepest part of the pockets in each patient in each time then it would be sent to microbial analysis for the detection of $A$. aclinomycetemcomitans and $P$. gingivalis.

Those patients are systemically healthy with residual pockets, previously treated for periodontal pockets. The eligibility criteria were that those after completion of comprehensive periodontal therapy since 3 to 24 months, presence, in the region from the distal aspect of the $2^{\text {nd }}$ molar to the distal aspect of the canine in the lower arch with a Probing Pocket Depth (PPD) $>4 \mathrm{~mm}$, bleeding upon probing.

Inclusion criteria, patients had at least twenty teeth, with a minimum of fourmultirooted teeth and four teeth per quadrant, all patients suffered from chronic periodontitis, $15 \%$ of the pockets were $>4 \mathrm{~mm}$ that bled upon probing.

Exclusion criteria included major systemic illnesses (i.e., diabetes mellitus, cancer, HIV, bone metabolic diseases or disorders that compromise wound healing, radiation or immunosuppressive therapy), antibiotics, anti-inflammatory drugs or other medication taken within the previous 4 months that may affect the outcome of the study, confirmed, and any physical limitations or restrictions that might preclude normal oral hygiene procedures. The smoking history was recorded, but smoking was not an exclusion criterion. Written informed consent was obtained from all included subjects. A patient number was attributed in ascending order. The deepest pocket in the area between the $2^{\text {nd }}$ molar and the distal aspect of the canine with PPD $>4 \mathrm{~mm}$, and BOP was designated as the study site.

Then follow up was done one after one month and another after 3 months and one after 6 months. Patient instructed how to wash his teeth and how to keep good oral hygiene between settings and within the follow up sessions.

\section{Investigation and Evaluation}

\section{Patients Examination}

\section{Clinical Examination}

This will done intra orally in each setting to detect the pocket depth with graduated probe in 9 areas from the distal aspect of the upper canine to the distal aspect of the $2^{\text {nd }}$ lower right molar 
as following (1_distal to $2^{\text {nd }}$ molar, 2_median aspect of the $2^{\text {nd }}$ molar, 3_mesial aspect of the $2^{\text {nd }}$ premolar, 4_median aspect of the $1^{\text {st }}$ molar, 5_distal to $1^{\text {st }}$ molar, 6_median aspect of the $2^{\text {nd }}$ premolar, 7_distal to $2^{\text {nd }}$ premolar, 8 median aspect of the $1^{\text {st }}$ premolar, 9_distal to $1^{\text {st }}$ premolar, distal aspect of the canine) and the deepest point from the pre-treatment setting tested in each time in the treatment settings every 3 days for 2 times and in each follow up setting one after month, other after 3 months and the last one after 6 months (Fig. 1).

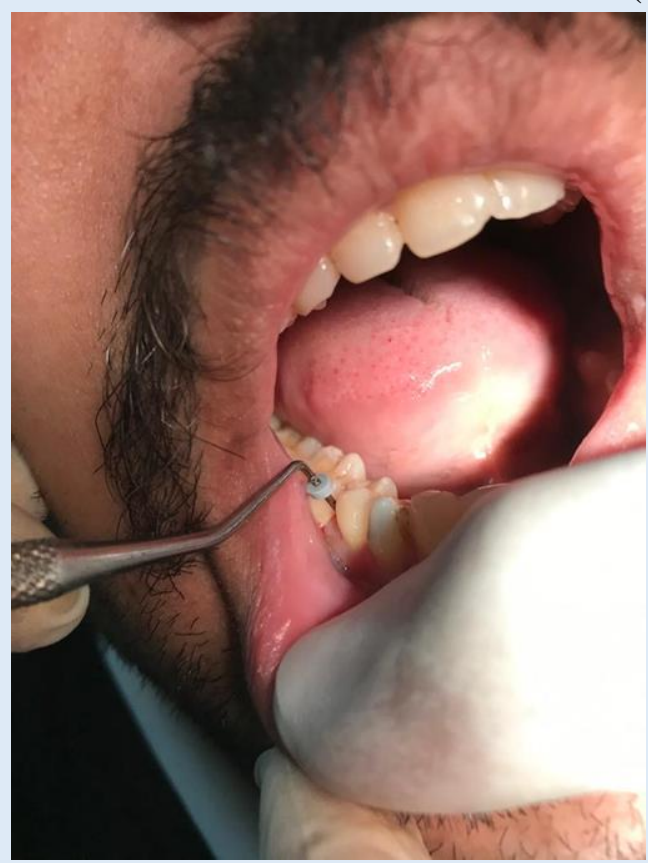

Figure 1: Pocket depth examination.

\section{Bleeding Examination}

Bleeding with probing tested in the pre-treatment setting and then tested in each time in the treatment settings every 3 days for 2 times and in each follow up setting one after month, other after 3 months and the last one after 6 months.

\section{Microbiologic Investigations}

\section{Sampling Procedure}

Periodontal pocket was sampled before and after high power diode laser and PDT in each patient for antibacterial evaluation by culture or PCR at different times.

\section{Culture Sample}

For microbial sampling, periodontal pocket were sampled before and after high power diode laser and PDT in each tooth. Three sterile paper points were introduced sequential into the full length of the periodontal pocket and kept in place for one minute. The paper points samples 
from the Periodontal pocket were immediately transferred to one $\mathrm{ml}$ of Brain Heart Infusion broth (BHI) transport medium and transport within one hour to microbiological laboratory.

\section{Sampling for PCR}

Periodontal pocket contents were absorbed into at least three paper points. These paper points were then transferred to cryotubes containing $1 \mathrm{ml}$ of 5\% Dimethyl Sulfoxide (DMSO) in Trypticase Soy Broth (TSB). Samples were then immediately frozen at $-20^{\circ} \mathrm{C}$ until they were processed (Fig. 2).

\section{Armamentarium}

1. Mouth mirror

2. Periodontal probe

3. Tweezer

4. Cheek retractor

5. Cotton rolls

6. Suction tip

7. Local anesthetic solution-Lignocaine with adrenaline 1:80,000 $8.3 \mathrm{ml}$ disposable syringe

8. Gauze pieces

9. G curettes

10. Diode laser

11. Ultra-sonic scaler

12. Paper point

13. Methyline blue

14. PCR-C1000 Gradient Thermal Cycler (BIO-RAD) 


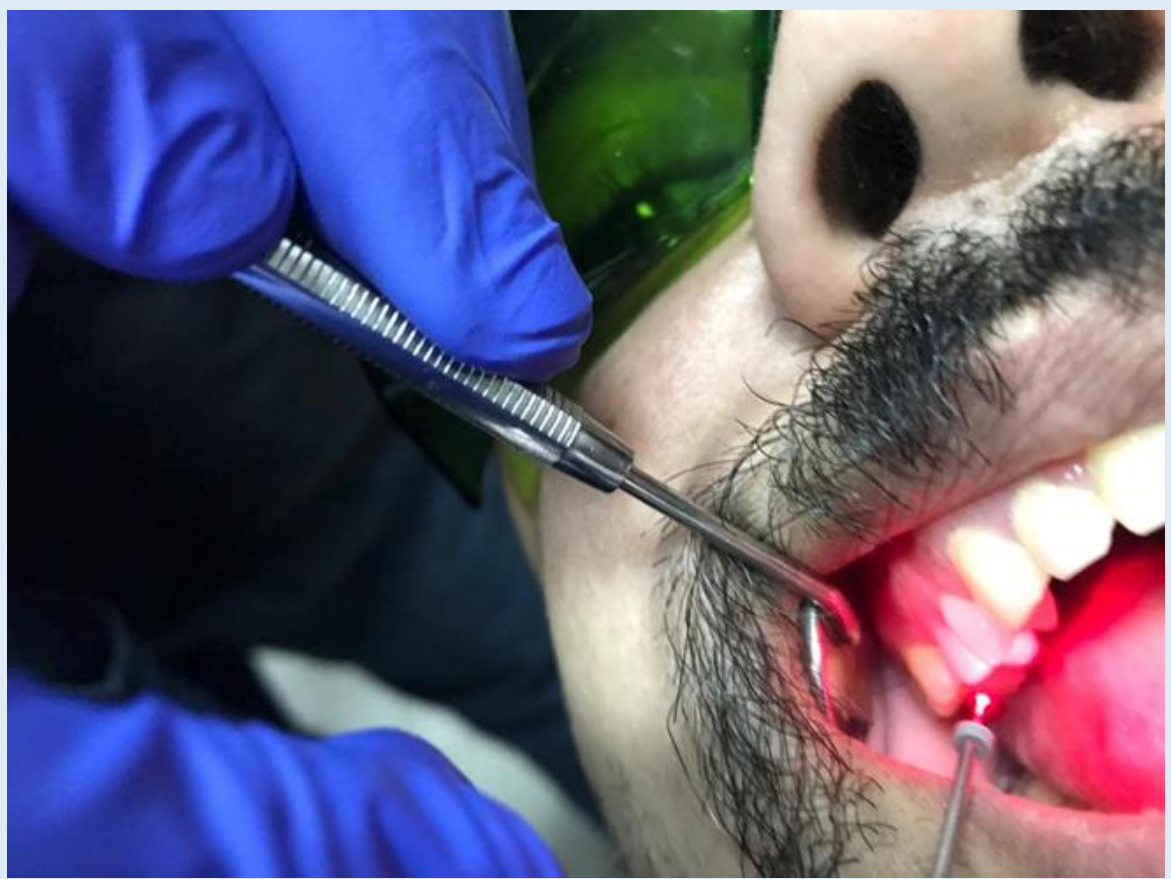

Figure 2: Diode laser application.

\section{Post-operative Instructions}

- Avoid using any commercially available mouth rinses

- Avoid vigorous brushing, eating hard and hot foods

- Follow the oral hygiene instructions regularly

- Patient demonstrated and motivated for modified bass brushing technique

\section{Statistical Analysis}

The statistical analysis was performed using the Statistical Package for the Social Sciences 24.0 (SPSS Inc. v.24.0; IBM, Chicago, IL, USA). Test of normality was conducted using the Shapiro-Wilk test in conjunction with histograms, P-P and Q-Q plots. Paired t-test was applied to determine the differences in the means of clinical parameters (PD, probing depth and CAL, clinical attachment level) between baseline and 3 months and baselineand 6 months within each group. One-Way ANOVA with repeated measures was used to find differences in the means of the clinical parameters (PD, probing depth and CAL: Clinical Attachment Level) between groups in the same period. The nonparametric McNemar's X2 test was applied to determine the differences in the proportions of clinical parameters (pocket depth, bleeding on probing, bacterial count) before, after, one month, 3 and 6 months later within each group. Cochran's Q test was used to find differences in the proportions of clinical parameters between groups in the same period. Relationships with a p-value $(p) \leq 0.05$ were considered as statistically significant. All reported p-values are two-sided. In the presentation of results,

Quriba MAA | Volume 2; Issue 1 (2021) | JDHOR-2(1)-022 | Research Article

Citation: Quriba MAA, et al. The Clinical Effect of Diode Laser in the Treatment of the Periodontal Pockets in Comparison with the Use of Photodynamic Therapy. J Dental Health Oral Res. 2021;2(1):118.

DOI: http://dx.doi.org/10.46889/JDHOR.2021.2105 
continuous variables are shown as means with Standard Deviation (SD), while frequencies with percentages are used for categorical variables $\mathrm{N}(\%)$.

\section{Results}

The current study was conducted to evaluate the effects of diode laser versus PDT in periodontitis treatment as non-surgical method of treatment. Thirty patients' males and females suffering from gingival pockets with age range from 20 to 65 years old from faculty of oral and dental medicine out clinics and selected randomly and divided in 2 groups each group contains fifteen patients. Group A received scaling and root planning in addition to $980 \mathrm{~nm}$ diode laser only without photosensitizer. Group B received scaling and root planning in addition to PDT.

\section{Demographics of the Patients}

Age

The mean age of group A was $35.2 \pm 13.18$, while in group B equalled $40.47 \pm 12.82$ with no statistically significant difference between both groups $(\mathrm{t}=-1.109, \mathrm{P}=0.277)$ as shown in table (00) and figure (00) (Table 1 and Fig. 3).

\begin{tabular}{|l|l|l|l|l|}
\hline & Group A & Group B & t & Sig \\
\hline Age & $35.2 \pm 13.18$ & $40.47 \pm 12.82$ & -1.109 & 0.277 \\
\hline
\end{tabular}

Table 1: Descriptive and inferential statistics of age among both groups.

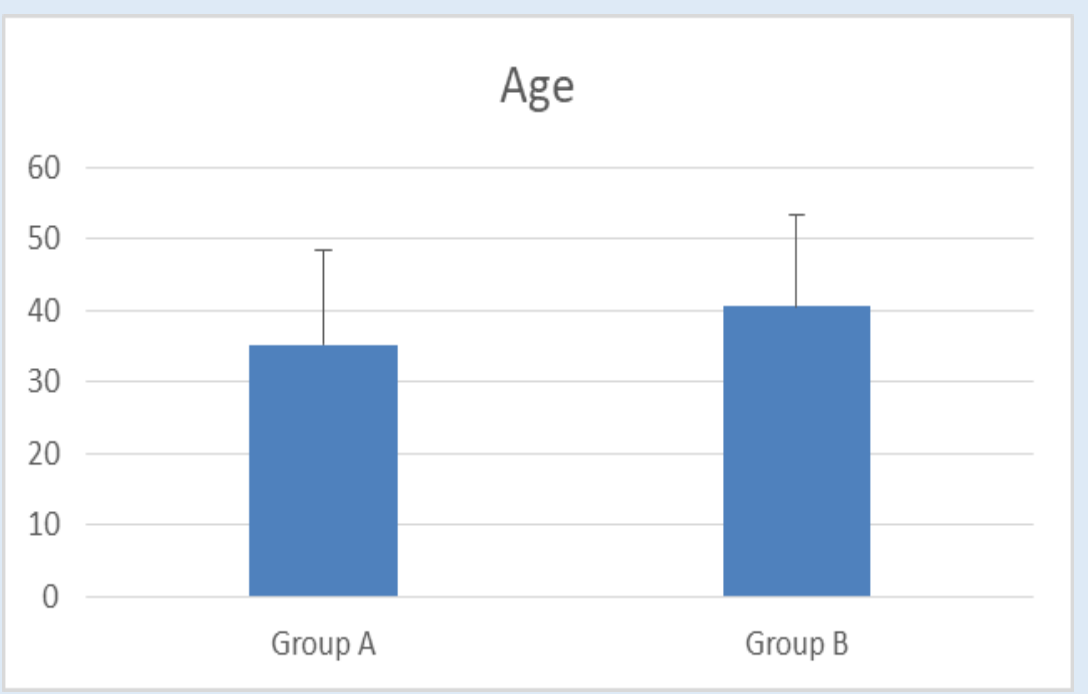

Figure 3: Mean and standard deviation of age among both groups.

Quriba MAA | Volume 2; Issue 1 (2021) | JDHOR-2(1)-022 | Research Article 


\section{Gender}

Group A include 8 males and 7 females while group B include 6 males and 9 females. The chisquare statistics showed no statistically significant differences between both groups when looking to gender distribution as shown in table (00) and figure (00) (Table 2 and Fig. 4).

\begin{tabular}{|l|l|l|l|l|l|}
\hline Gender & Group A & Group B & Total & Chi value & Sig. \\
\hline Male & 8 & 6 & 14 & 0.536 & 0.464 \\
\hline Female & 7 & 9 & 16 & & \\
\hline Total & 15 & 15 & 30 & & \\
\hline
\end{tabular}

Table 2: Frequency and Chi square of gender among both groups.

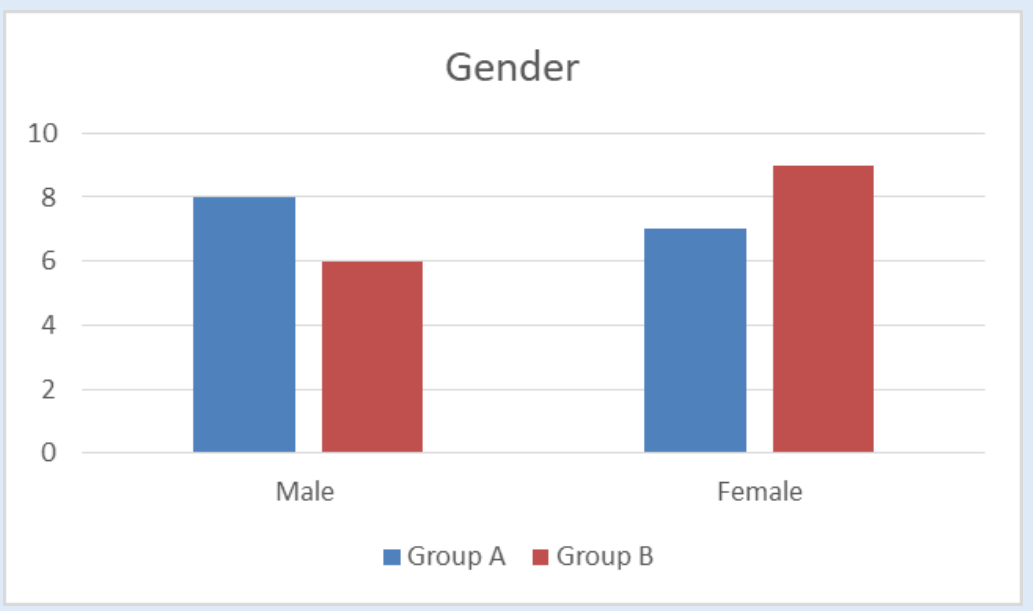

Figure 4: Frequency of male and females among both groups.

\section{Deepest Site}

Regarding the deepest site, there were no statistically significant differences between both Groups as deepest site is pocket depth at first molar distal (Table 3,4 and Fig. 5).

\begin{tabular}{|c|c|c|c|c|c|}
\hline Deepest site & Group A & Group B & Total & Chi value & Sig. \\
\hline PD_2M_Dis & 5 & 3 & 8 & 2.083 & 0.72 \\
\hline PD_1M_Dis & 7 & 9 & 16 & & \\
\hline PD_1M_Mid & 1 & 1 & 2 & & \\
\hline PD_2PM_Dis & 2 & 1 & 3 & & \\
\hline PD_2PM_Mid & 0 & 1 & 1 & & \\
\hline Total & 15 & 15 & 30 & & \\
\hline
\end{tabular}

PD: Pocket depth, 1M: First Molar, 2M: Second Molar, 1PM: First Premolar, 2PM:

Second Premolar, Dis.: Distal, Mid: Medial, *: Significant

Table 3: Frequency and Chi square of deepest site among both groups. 


\section{Deepest site}

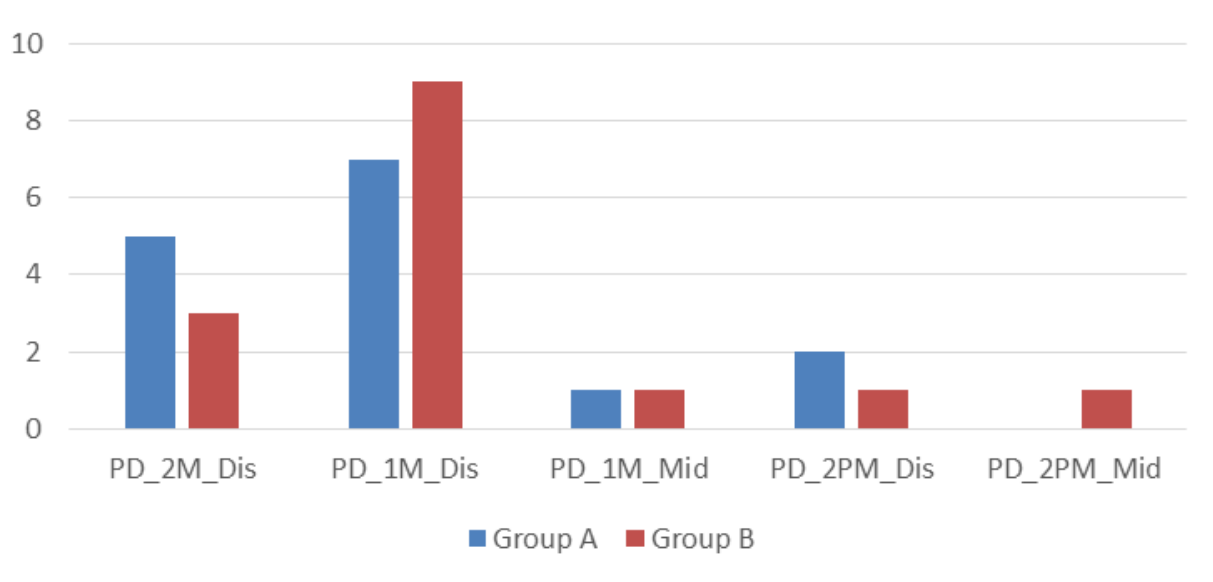

Figure 5: Frequency of deepest site among both groups.

\begin{tabular}{|c|c|c|c|c|}
\hline & Group A & Group B & $\mathbf{t}$ & Sig. \\
\hline PD_2M_Dis & $5.53 \pm 1.05$ & $5.7 \pm 0.95$ & -0.4 & 0.652 \\
\hline PD_2M_Mid & $5.43 \pm 0.98$ & $5.5 \pm 0.78$ & -0.206 & 0.838 \\
\hline PD_1M_Dis & $5.7 \pm 0.88$ & $6.07 \pm 0.86$ & -1.15 & 0.26 \\
\hline PD_1M_Mid & $5.3 \pm 0.93$ & $5.5 \pm 0.75$ & -0.65 & 0.521 \\
\hline PD_2PM_Dis & $5.3 \pm 0.85$ & $5.5 \pm 0.92$ & -0.619 & 0.541 \\
\hline PD_2PM_Mid & $5 \pm 0.74$ & $5.13 \pm 0.68$ & -0.512 & 0.613 \\
\hline PD_1PM_Dis & $4.93 \pm 0.83$ & $5.03 \pm 0.78$ & -0.34 & 0.736 \\
\hline PD_1PM_Mid & $4.53 \pm 0.84$ & $4.67 \pm 0.74$ & -0.461 & 0.648 \\
\hline Canine_Dis & $4.17 \pm 0.82$ & $4.3 \pm 0.7$ & -0.48 & 0.635 \\
\hline \multicolumn{5}{|c|}{$\begin{array}{l}\text { PD: Pocket depth, 1M: First Molar, 2M: Second Molar, 1PM: } \\
\text { First Premolar, 2PM: Second Premolar, Dis.: Distal, Mid: } \\
\text { Medial, *: Significant }\end{array}$} \\
\hline
\end{tabular}

Table 4: Descriptive and inferential statistics of basic measures among both groups.

\section{Measurement Variables}

\section{Pocket Depth}

The pocket depth was measured in both groups pre- and post-treatment with follow up at one, three and six months. Group A pre-treatment value was $6.1 \pm 0.8$ while the post treatment value was $6.1 \pm 1.29$ and follow up values at one, three and six months were $3.37 \pm 0.9,2.57 \pm 0.68$ and $2.4 \pm 0.46$ with total improvement percentage of $60.66 \%$ and statistically significant effect of treatment $(\mathrm{F}=94.939, \mathrm{P}=0.000)$. 
Group B pre-treatment value was $6.3 \pm 0.74$ while the post treatment value was $3.77 \pm 0.74$ and follow up values at one, three and six months were $2.67 \pm 0.61,2.2 \pm 0.5$ and $1.3 \pm 0.51$ with total improvement percentage of $79.37 \%$ and statistically significant effect of treatment $(\mathrm{F}=148.340$, $\mathrm{P}=0.000)$.

Regarding between group comparison, there were statistically significant differences between both groups overall $(\mathrm{F}=21.122, \mathrm{P}=0.000)$ with statistically significant differences in post treatment value $(\mathrm{F}=2.333, \mathrm{P}=0.000)$ and follow up at one $(\mathrm{F}=0.700, \mathrm{P}=0.019)$ and six months $(\mathrm{F}=1.100, \mathrm{P}=0.000)$ (Table 5 and Fig. 6).

\begin{tabular}{|l|l|l|l|l|}
\hline & Group A & Group B & F & Sig. \\
\hline Pre-PD & $6.1 \pm 0.8$ & $6.3 \pm 0.74$ & -0.2 & 0.481 \\
\hline PostI-PD & $6.1 \pm 1.29$ & $3.77 \pm 0.74$ & $2.333^{*}$ & 0 \\
\hline Post1M-PD & $3.37 \pm 0.9$ & $2.67 \pm 0.61$ & $.700 *$ & 0.019 \\
\hline Post3M-PD & $2.57 \pm 0.68$ & $2.2 \pm 0.5$ & 0.367 & 0.101 \\
\hline Post6M-PD & $2.4 \pm 0.46$ & $1.3 \pm 0.51$ & $1.100^{*}$ & 0 \\
\hline Change & DE-60.66\% & DE-79.37\% & & \\
\hline F & $94.939 *$ & $148.340^{*}$ & $21.122^{*}$ & \\
\hline Sig & 0 & 0 & & 0 \\
\hline PD: Pocket depth, 1M: One month, 3M: Three months, 6M: six months, *: Significant
\end{tabular}

Table 5: Descriptive and inferential statistics of Pocket depth among both groups at different time intervals.

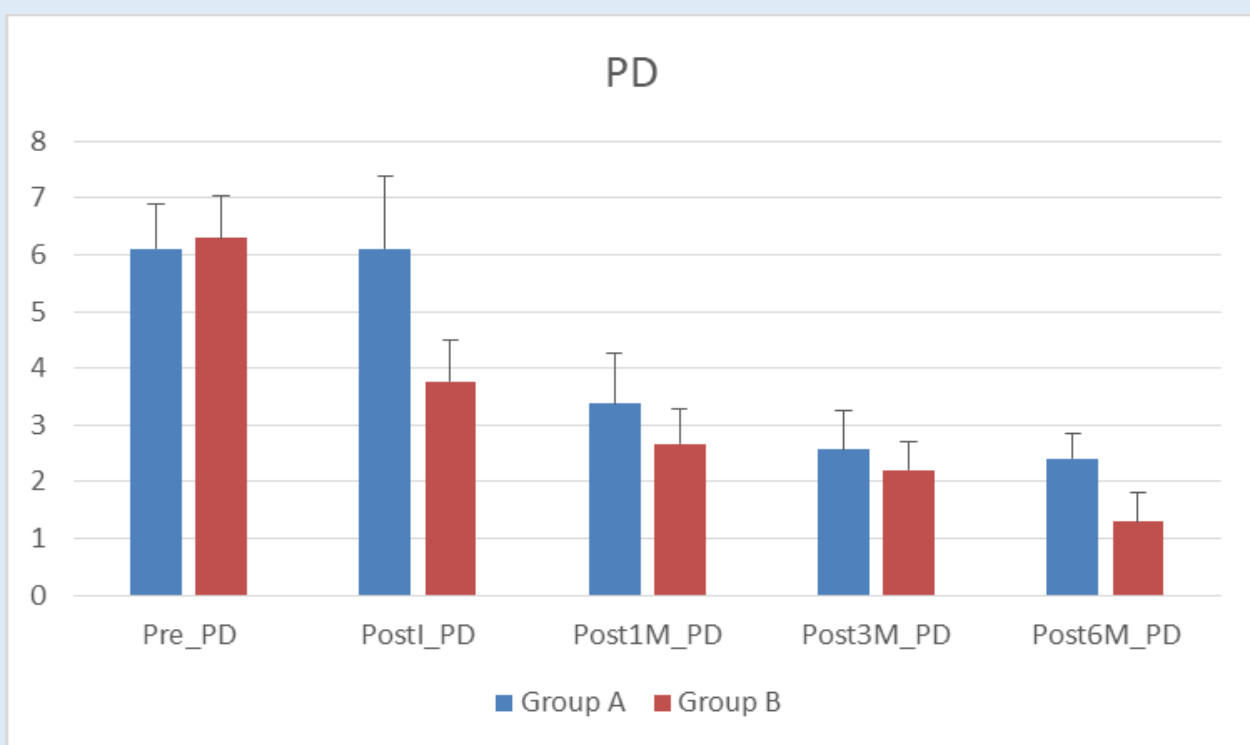

Figure 6: Mean and standard deviation of Pocket depth among both groups at different time intervals.

Quriba MAA | Volume 2; Issue 1 (2021) | JDHOR-2(1)-022 | Research Article

Citation: Quriba MAA, et al. The Clinical Effect of Diode Laser in the Treatment of the Periodontal

Pockets in Comparison with the Use of Photodynamic Therapy. J Dental Health Oral Res. 2021;2(1):118. 


\section{Bacterial Count}

The Bacterial count was measured in both groups pre- and post-treatment with follow-up at one, three and six months. Group A pre-treatment value was $89545.33 \pm 17592.59$ while the post treatment value was $50756.67 \pm 11571.26$ and follow up values at one, three and six months were $31713.33 \pm 6709.6,19126.67 \pm 6739.28$ and $10578 \pm 5163.54$ with total improvement percentage of $88.19 \%$ and statistically significant effect of treatment $(\mathrm{F}=83.186, \mathrm{P}=0.000)$.

Group B pre-treatment value was $79427.33 \pm 14923.56$ while the post treatment value was $42940 \pm 16402.45$ and follow up values at one, three and six months were $26738.67 \pm 12819.17$, $15954.23 \pm 8976.99$ and $10773.33 \pm 5700.13$ with total improvement percentage of $86.44 \%$ and statistically significant effect of treatment $(\mathrm{F}=110.109, \mathrm{P}=0.000)$.

Regarding between group comparison, there were no statistically significant differences between both groups overall $(\mathrm{F}=2.375, \mathrm{P}=0.056)$ with no statistically significant differences in neither post treatment value $(\mathrm{F}=7816.667, \mathrm{P}=0.143)$ nor follow up at one $(\mathrm{F}=4974.667$, $\mathrm{P}=0.194)$, three $(\mathrm{F}=3172.44, \mathrm{P}=0.283)$ and six months $(\mathrm{F}=195.333, \mathrm{P}=0.922)$ (Table 6 and Fig. 7).

\begin{tabular}{|l|l|l|l|l|}
\hline & Group A & Group B & F & Sig. \\
\hline Pre-BC & $89545.33 \pm 17592.59$ & $79427.33 \pm 14923.56$ & 10118 & 0.1 \\
\hline PostI-BC & $50756.67 \pm 11571.26$ & $42940 \pm 16402.45$ & 7816.667 & 0.143 \\
\hline Post1M-BC & $31713.33 \pm 6709.6$ & $26738.67 \pm 12819.17$ & 4974.667 & 0.194 \\
\hline Post3M-BC & $19126.67 \pm 6739.28$ & $15954.23 \pm 8976.99$ & 3172.44 & 0.283 \\
\hline Post6M-BC & $10578 \pm 5163.54$ & $10773.33 \pm 5700.13$ & -195.333 & 0.922 \\
\hline Change & DE-88.19\% & DE-86.44\% & & \\
\hline F & $83.186^{*}$ & $110.109^{*}$ & 2.375 & \\
\hline Sig & 0 & 0 & & 0.056 \\
\hline BC: & & & & \\
\hline
\end{tabular}

BC: Bacterial count, 1M: One month, 3M: Three months, 6M: six months, *: Significant

Table 6: Descriptive and inferential statistics of Bacterial count among both groups at different time intervals. 


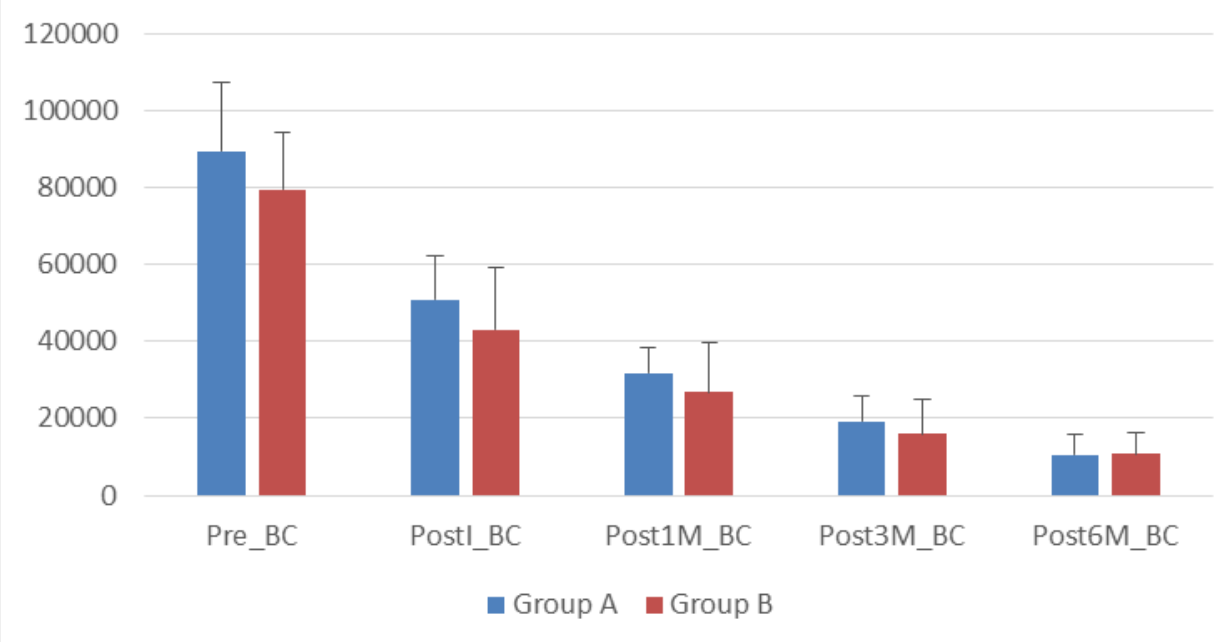

Figure 7: Mean and standard deviation of bacterial count among both groups at different time intervals.

\section{Bleeding Examination}

The Bleeding examination was measured in both groups pre- and post-treatment with follow up at one, three and six months. Group A pre-treatment value was $4.8 \pm 0.85$ while the post treatment value was $2.47 \pm 1.1$ and follow up values at one, three and six months were $2.57 \pm 1.16,2.13 \pm 0.83$ and $1.67 \pm 0.8$ with total improvement percentage of $65.21 \%$ and statistically significant effect of treatment $(\mathrm{F}=52.738, \mathrm{P}=0.000)$.

Group B pre-treatment value was $5 \pm 0.94$ while the post treatment value was $2.93 \pm 0.74$ and follow up values at one, three and six months were $2.93 \pm 0.78,2.4 \pm 0.74$ and $1.93 \pm 0.72$ with total improvement percentage of $61.4 \%$ and statistically significant effect of treatment $(\mathrm{F}=47.084, \mathrm{P}=0.000)$.

Regarding between group comparison, there were no statistically significant differences between both groups overall $(\mathrm{F}=0.316, \mathrm{P}=0.866)$ with no statistically significant differences in neither post treatment value $(\mathrm{F}=-0.467, \mathrm{P}=0.184)$ nor follow up at one $(\mathrm{F}=0.367, \mathrm{P}=0.318)$, three $(\mathrm{F}=-0.267, \mathrm{P}=0.361)$ and six months $(\mathrm{F}=-0.267, \mathrm{P}=0.346)$ (Table 7 and Fig. 8).

\begin{tabular}{|l|l|l|l|l|}
\hline & Group A & Group B & F & Sig. \\
\hline Pre-BLE & $4.8 \pm 0.85$ & $5 \pm 0.94$ & -0.2 & 0.545 \\
\hline PostI-BLE & $2.47 \pm 1.1$ & $2.93 \pm 0.74$ & -0.467 & 0.184 \\
\hline Post1M-BLE & $2.57 \pm 1.16$ & $2.93 \pm 0.78$ & -0.367 & 0.318 \\
\hline Post3M-BLE & $2.13 \pm 0.83$ & $2.4 \pm 0.74$ & -0.267 & 0.361 \\
\hline
\end{tabular}

Quriba MAA | Volume 2; Issue 1 (2021) | JDHOR-2(1)-022 | Research Article 


\begin{tabular}{|l|l|l|l|l|}
\hline Post6M-BLE & $1.67 \pm 0.8$ & $1.93 \pm 0.72$ & -0.267 & 0.346 \\
\hline Change & DE-65.21\% & DE-61.4\% & & \\
\hline F & $52.738^{*}$ & $47.084^{*}$ & 0.316 & \\
\hline Sig & 0 & 0 & & 0.866 \\
\hline $\begin{array}{l}\text { BLE: Bleeding examination, 1M: One month, 3M: Three months, 6M: six } \\
\text { months, *: Significant }\end{array}$
\end{tabular}

Table 7: Descriptive and inferential statistics of bleeding examination among both groups at different time intervals.

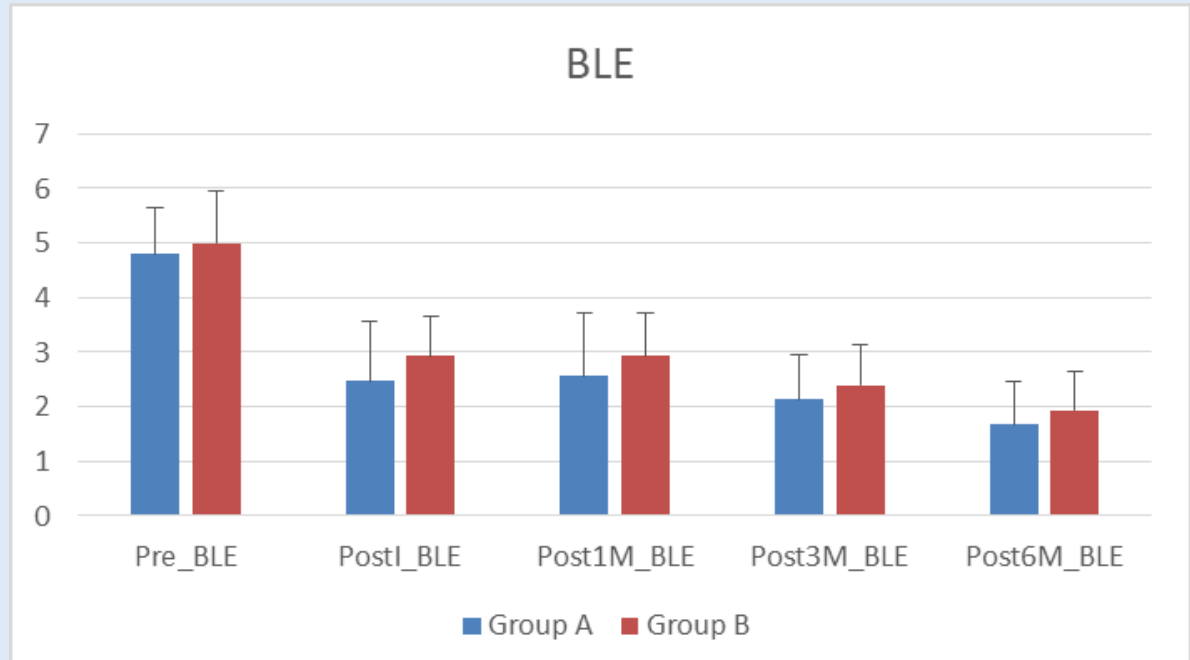

Figure 8: Mean and standard deviation of bleeding examination among both groups at different time intervals.

\section{Multivariate Analysis}

Regarding overall improvement of group, $\mathrm{A}$ and $\mathrm{B}$, there was statistically significant improvement in group $\mathrm{A}(\mathrm{F}=114.697, \mathrm{P}=0.000)$ and in group $\mathrm{B}(\mathrm{F}=126.308, \mathrm{P}=0.000)$. Also, there was statistically significant difference between both groups $(\mathrm{F}=5.904, \mathrm{P}=0.000)$ (Table 8).

\begin{tabular}{|l|l|l|l|l|}
\hline & Group A & Group B & F & Sig. \\
\hline F & $114.697^{*}$ & $126.308^{*}$ & $5.904^{*}$ & \\
\hline Sig & 0 & 0 & & 0 \\
\hline
\end{tabular}

Table 8: Multivariate analysis of all variables in both groups and in total. 


\section{Discussion}

The current study was conducted to evaluate the effects of diode laser versus PDT in periodontitis treatment as non-surgical method of treatment. Thirty patients' males and females suffering from gingival pockets with age range from 20 to 65 years old from faculty of oral and dental medicine out clinics and selected randomly and divided in 2 groups each group contains fifteen patients. Group A received scaling and root planning in addition to $980 \mathrm{~nm}$ diode laser only without photosensitizer. Group B received scaling and root planning in addition to PDT [15-18].

There was statistically significant improvement in group $\mathrm{A}(\mathrm{F}=114.697, \mathrm{P}=0.000)$ and in group $\mathrm{B}(\mathrm{F}=126.308, \mathrm{P}=0.000)$. Also, there was statistically significant difference between both groups $(\mathrm{F}=5.904, \mathrm{P}=0.000)$ with most difference in Pocket depth only $(\mathrm{F}=21.122, \mathrm{P}=0.000)$ with statistically significant differences in post treatment value $(\mathrm{F}=2.333, \mathrm{P}=0.000)$ and follow up at one $(\mathrm{F}=0.700, \mathrm{P}=0.019)$ and six months $(\mathrm{F}=1.100, \mathrm{P}=0.000)$.

The results of studies done on the impact of PDT with and use of laser only as an adjunctive way of treatment for chronic periodontitis are conflicting. Although in most of these studies, laser diode has been used, but none of them mentioned which types of laser, photosensitizer, wavelength, power and intensity are more effective. (Chan Y, Lai CH, 2003).

\section{Diode Laser for Periodontal Pockets}

To investigate and compare the clinical, microbial, and inflammatory effects of a diode laser as an adjunct to (SRP) in comparison with SRP alone for the treatment of generalized aggressive periodontitis (GAgP). Methods: Using a split-mouth technique, thirty one volunteers with GAgP were participated in the study. The upper arch quadrants were assigned to SRP and diode laser or SRP alone. Volunteers were tested for clinical, microbiological, and inflammatory mediator changes for a year. (CAL) was the first outcome to be chosen. And also, subgingival samples and (GCF) analysis for inflammatory mediators were analyzed and the results was compared in, both treatments showed an improvement in periodontal parameters at 1 year. Although, SRP with diode laser showed high improvement in Pocket Depth (PD; $2.56 \pm 0.44$ vs. $3.36 \pm 0.51 \mathrm{~mm}, \mathrm{p}<0.05)$ and CAL $(3.47 \pm 0.25$ vs. $4.11 \pm 0.26 \mathrm{~mm}, \mathrm{p}<0.05)$ values are compared to SRP alone. 


\section{PDT for Periodontal Pockets}

Use of a Photo Dynamic Therapy with open flap debridement of the in the surgical treatment of SCP: is significantly improved clinical periodontal parameters and eliminates periodontal pathogens of the red complex more effectively (NCT02734784) (Martins et al., 2017) and this came in agreement with the current study.

\section{Diode laser versus PDT for periodontal pockets}

Total removal of bacteria from pockets is not possible with mechanical treatment, hence it is supplemented with antibiotics5. One of The draw backs of chemotherapy are bacterial resistance and side effects after systemic administration. Photodynamic therapy avoids that by adjuncting irradiation with laser with the PS dye. Methylene blue used as a photosensitizer in this study, as it was reported to be the safest photosensitizers for the treatment of periodontal disease. It has a better effect on sites with deep periodontal pockets, furcation's and root concavity [18].

Considered the best clinical results, the laser diode can be routinely associated with mechanical therapy (SRP) in the treatment of periodontal pockets of patients with severe chronic periodontitis. In the present study patients with chronic periodontitis and the adjunctive use of PDT to scaling and root planning may result, on a short-term basis (up to $3^{\text {rd }}$ week), in

1. Comparable reductions in Plaque Index (PI) score when compared with scaling and root planning alone

2. Comparable higher probing pocket depth reductions and clinical attachment level gains when compared with scaling and root planning alone

3. There is more reductions in bacterial count than with scaling and root planning alone

The uses of Photodynamic therapy as an adjunctive therapy for periodontal disease showed bactericidal effect and target pathogens more. The combination of laser therapy with conventional procedures allows, in fact, to obtain a more effective decontamination of the pocket, in addition to this the recolonization by bacteria is slower than the sites treated only with scaling and root planning. Moritz, et al., and Angelov, et al., showed that diode laser therapy can significantly improve periodontal pocket healing and periodontal indices [19].

\section{References}

1. Ramberg P, Rosling B, Serino G, Hellström MK, Socransky SS, Lindhe J. The long-term effect of systemic tetracycline used as an adjunct to non-surgical treatment of advanced periodontitis. J Clin Periodontol. 2001;28(5):446-52.

Quriba MAA | Volume 2; Issue 1 (2021) | JDHOR-2(1)-022 | Research Article 
2. Hamblin MR, Hasan T. Photodynamic therapy: a new antimicrobial approach to infectious disease? Photochemical and Photobiological Sci. 2004;3(5):436-50.

3. Azarpazhooh A, Shah PS, Tenenbaum HC, Goldberg MB. The effect of photodynamic therapy for periodontitis: A systematic review and meta-analysis. J Periodontol. 2010;81(1):4-14.

4. Kamma JJ, Vasdekis VG, Romanos GE. The short-term effect of diode laser $(980 \mathrm{~nm})$ treatment on aggressive periodontitis. Evaluation of clinical and microbiological parameters. J Oral Laser Applications. 2006;6(2).

5. Quirynen M, Teughels W, Van Steenberghe D. Impact of antiseptics on one-stage, full-mouth disinfection. J Clin Periodontol. 2006;33(1):49-52.

6. Kornman KS, Page RC, Tonetti MS. The host response to the microbial challenge in periodontitis: assembling the players. Periodontol 2000. 1997;14(1):33-53.

7. Dutt P, Rathore PK, Khurana D. Chlorhexidine-An antiseptic in periodontics. IOSR-JDMS. 2014;13(9):858.

8. Sharwani A, Jerjes W, Salih V, MacRobert AJ, El-Maaytah M, Khalil HS, et al. Fluorescence spectroscopy combined with 5-aminolevulinic acid-induced protoporphyrin IX fluorescence in detecting oral premalignancy. Journal of Photochemistry and Photobiology B: Biology. 2006;83(1):27-33.

9. Van Winkelhoff AJ, Rams TE, Slots J. Systemic antibiotics in periodontics. Periodontology (2000). 1996;10:45-78.

10. Franco Neto CA, Parolo CC, Rösing CK, Maltz M. Comparative analysis of the effect of two chlorhexidine mouthrinses on plaque accumulation and gingival bleeding. Brazilian Oral Res. 2008;22(2):139-44.

11. Cionca N, Giannopoulou C, Ugolotti G, Mombelli A. Amoxicillin and metronidazole as an adjunct to fullmouth scaling and root planing of chronic periodontitis. J Periodontol. 2009;80(3):364-71.

12. Herrera D, Sanz M, Jepsen S, Needleman I, Roldán S. A systematic review on the effect of systemic antimicrobials as an adjunct to scaling and root planing in periodontitis patients. J Clinical Periodontol. 2002;29:136-59.

13. Johansson A, Buhlin K, Koski R, Gustafsson A. The immunoreactivity of systemic antibodies to Actinobacillus actinomycetemcomitans and Porphyromonas gingivalis in adult periodontitis. Euro J Oral Sciences. 2005;113(3):197-202.

14. Ryan ME. Nonsurgical approaches for the treatment of periodontal diseases, Dent Clin N Am. 2005;49( 2005)611-36.

15. Al-Abdaly M, El-Refai AN, Gouda U, Abdel Atty H. Evaluation of topical application of CHLO-site (chlorhexidine gel) in management of chronic periodontitis. Suez Canal Univ Med J. 2008;11(1):35-40.

16. Ochsner M. Photophysical and photobiological processes in the photodynamic therapy of tumours. J Photochemistry and Photobiology B: Biology. 1997;39(1):1-8.

17. Renvert S, Wikström M, Dahlén G, Slots J, Egelberg J. Effect of root debridement on the elimination of Actinobacillus actinomycetemcomitans and Bacteroides gingivalis from periodontal pockets. J Clin Periodontol. 1990;17(6):345-50.

18. Schwarz F, Aoki A, Becker J, Sculean A. Laser application in non-surgical periodontal therapy: a systematic review. J Clin Periodontol. 2008;35:29-44.

19. Wainwright M. Photodynamic Antimicrobial Chemotherapy (PACT). J Antimicrobial Chemotherapy. 1998;42(1):13-28. 